\title{
Soluble Adenylyl Cyclase Is Not Required for Axon Guidance to Netrin-1
}

\author{
Simon W. Moore, ${ }^{1}$ Karen Lai Wing Sun, ${ }^{1}$ Fang Xie, ${ }^{2}$ Philip A. Barker, ${ }^{1}$ Marco Conti, ${ }^{2}$ and Timothy E. Kennedy ${ }^{1}$ \\ ${ }^{1}$ Centre for Neuronal Survival, Montreal Neurological Institute, Department of Neurology and Neurosurgery, McGill University, Montreal, Quebec, Canada \\ H3A 2B4, and 2Division of Reproductive Biology, Department of Obstetrics and Gynecology, Stanford University School of Medicine, Stanford, California \\ 94305-5317
}

During development, axons are directed to their targets by extracellular guidance cues. The axonal response to the guidance cue netrin-1 is profoundly influenced by the concentration of cAMP within the growth cone. In some cases, cAMP affects the sensitivity of the growth cone to netrin-1, whereas in others it changes the response to netrin-1 from attraction to repulsion. The effects of cAMP on netrin-1 action are well accepted, but the critical issue of whether cAMP production is activated by a netrin-1 induced signaling cascade remains uncertain. A previous report has suggested that axon guidance in response to netrin-1 requires cAMP production mediated by soluble adenyl cyclase (sAC). We have used genetic, molecular and biochemical strategies to assess this issue. Surprisingly, we found only extremely weak expression of sAC in embryonic neurons and determined that, under conditions where netrin-1 directs axonal pathfinding, exposure to netrin-1 does not alter cAMP levels. Furthermore, although netrin-1-deficient mice exhibit major axon guidance defects, we show that pathfinding is normal in sAC-null mice. Therefore, although cAMP can alter the response of axons to netrin-1, we conclude that netrin-1 does not alter cAMP levels in axons attracted by this cue, and that sAC is not required for axon attraction to netrin-1.

Key words: spinal commissural neurons; dorsal root ganglion; DRG; nerve growth factor; NGF; protein kinase A; PKA; pituitary adenylate cyclase-activating polypeptide; PACAP

\section{Introduction}

cAMP is generated by adenylyl cyclases from ATP and is degraded by phosphodiesterases (Tasken and Aandahl, 2004). Mammals express one soluble and nine transmembrane isoforms of adenylyl cyclase. Transmembrane adenylyl cyclases are typically activated by G-proteins, whereas activity of soluble adenylyl cyclase is increased by bicarbonate ions (Chen et al., 2000; Cooper, 2003). Robust soluble adenyl cyclase (sAC) expression is found in testis and low levels of expression have been reported in various tissues (Chen et al., 2000; Sinclair et al., 2000; Schmid et al., 2007). Mice rendered null for sAC show no gross abnormalities and the only phenotype reported for these animals is male infertility (Esposito et al., 2004).

During development, axons are directed to their targets along defined pathways by extracellular cues (for review, see Huber et al., 2003). In the embryonic spinal cord, commissural axons are guided ventrally by netrin-1 secreted by the floor plate (Serafini et al., 1994, 1996; Kennedy et al., 1994). Netrin-1 binding to its

Received Sept. 18, 2007; accepted Feb. 27, 2008.

This work was supported by the Canadian Institutes of Health Research and National Institute of Health Grant R01 HD-31544. We thank Dr. Adriana Di Polo for comments on this manuscript and Nathalie Marcal for technical assistance. T.E.K. is a Killam Foundation Scholar and was supported by a Senior Chercheur-Boursier Award from the Fonds de la Recherche en Santé du Québec. S.W.M. was supported by Lloyd Carr-Harris and Canadian Institutes of Health Research studentships.

The authors declare no competing financial interests.

Correspondence should be addressed to Timothy E. Kennedy at the above address. E-mail: timothy.kennedy@mcgill.ca.

DOI:10.1523/JNEUROSCI.0547-08.2008

Copyright $\odot 2008$ Society for Neuroscience $\quad$ 0270-6474/08/283920-05\$15.00/0 receptor deleted in colorectal cancer (DCC) on commissural axons causes N-WASP (neuronal Wiskott-Aldrich syndrome protein), Pak1 (p21-activated kinase 1), and FAK (focal adhesion kinase) to associate with the intracellular domain of DCC and induces activation of phospholipase $\mathrm{C}$ and the Rho GTPases Rac and Cdc42 (for review, see Barallobre et al., 2005). These effectors collaborate to alter the axonal cytoskeleton to mediate turning in response to netrin-1.

cAMP signaling can regulate the sensitivity of the axon to netrin-1 or cause it to switch from being an attractant to a repellent cue (Ming et al., 1997; Hopker et al., 1999; Moore and Kennedy, 2006). Early reports suggested that netrin-1 increases cAMP in dissociated Xenopus retinal neurons, but we have shown that cAMP levels are not altered by netrin-1 in rat spinal commissural neurons (Hopker et al., 1999; Bouchard et al., 2004; Moore and Kennedy, 2006). In contrast, our findings indicate that increasing the concentration of cytosolic cAMP and activating PKA enhances chemoattraction to netrin-1 by recruiting DCC to the plasma membrane of commissural neurons. We were therefore intrigued by a report indicating that sAC-dependent cAMP production is activated by netrin-1 and is essential for attractant responses by embryonic dorsal root ganglion (DRG) neurons and in spinal commissural neurons (Wu et al., 2006). Here, we demonstrate that embryonic DRG and spinal commissural neurons express only very low levels of sAC and do not exhibit changes in intracellular cAMP levels when exposed to netrin-1. Furthermore, we report that sAC knock-out mice exhibit no defect in their spinal ventral commissure, a hallmark of netrin-1 
deficiency. We conclude that SAC and cAMP production are not required for axonal chemoattraction to netrin-1.

\section{Materials and Methods}

Reagents. Forskolin, 5-fluorodeoxyuridine (FdU), 3-isobutyl-1methylxanthine (IBMX), DNase, Hoechst 33258, and poly-D-lysine (PDL; 70-150 kDa) were obtained from Sigma-Aldrich (Missisauga, Canada). Neurobasal, fetal bovine serum, B-27 supplement, GlutaMAX-1, penicillin-streptomycin, $\mathrm{Ca}^{2+} / \mathrm{Mg}^{2+}$-free HBSS, and goat anti-rabbit Alexa 488 were purchased from Invitrogen Canada (Burlington, Ontario, Canada). Rabbit anti-neurofilament protein M (NFM) antibody was purchased from Millipore Bioscience Research Reagents (Temecula, CA). Tuj1 antibody was purchased from Covance Research Products (Emeryville, CA). Pituitary adenylate cyclase-activating polypeptide-38 (PACAP-38) was purchased from EMD Biosciences (San Diego, CA). Recombinant netrin-1 protein was purified from an HEK 293 (human embryonic kidney 293)-EBNA (Epstein-Barr nuclear antigen) cell line secreting netrin-1 as described previously (Serafini et al., 1994; Shirasaki et al., 1996). Nerve growth factor (NGF; 2.5S) was obtained from Cedarlane Labs (Burlington, Ontario, Canada).

Cell culture. Staged pregnant Sprague Dawley rats were obtained from Charles River Canada (St. Constant, Quebec, Canada). Spinal commissural neuron cultures were prepared from embryonic day 14 (E14; vaginal plug at E1) Sprague Dawley rats, as described previously (Bouchard et al., 2004). Cells were plated and cultured in six-well culture Falcon plates (Becton Dickinson, Franklin Lakes, NJ) previously coated with $2 \mu \mathrm{g} / \mathrm{cm}^{2}$ $\mathrm{PDL}$ for $2 \mathrm{~h}$ at room temperature.

DRGs were isolated from E15 Sprague Dawley rat embryos, as described previously (Hall, 2006). For explant experiments, five DRGs centered on each forelimb bud were selected and embedded in bovine dermal collagen (Inamed, Santa Barbara, CA). For dissociated cultures, DRGs between the two limb buds were used. Dissociated DRGs were plated on and cultured in six-well culture Falcon plates (Becton Dickinson) previously coated at room temperature with $2 \mu \mathrm{g} / \mathrm{cm}^{2} \mathrm{PDL}$ for $2 \mathrm{~h}$ and then $1 \mu \mathrm{g} / \mathrm{cm}^{2}$ fibronectin for another $2 \mathrm{~h}$. Both explant and dissociated DRG cultures were cultured in neurobasal supplemented with $2 \%$ B-27, 2 mm GlutaMAX-1, $100 \mathrm{U} / \mathrm{ml}$ penicillin, $100 \mu \mathrm{g} / \mathrm{ml}$ streptomycin, $0.08-75 \mathrm{ng} / \mathrm{ml} \mathrm{NGF}$, and $20 \mu \mathrm{M}$ FdU. Explant cultures were fixed after $14 \mathrm{~h}$ and labeled with Tuj1 antibody and Hoechst 33258; outgrowth was quantified with Image J (NIH) as the difference in area between Tuj1 and Hoechst 33258 labeling. For dissociated DRG cultures, the media was replaced after the first $24 \mathrm{~h}$.

$R T$-PCR analysis. Total RNA was extracted from flash-frozen adult rat testis (a gift from Drs. Craig Mandato and Louis Hermo, McGill University, Montreal, Quebec, Canada), adult mouse testis, as well as adult rat brain, embryonic spinal cord, 2 d in vitro (DIV) E14 spinal commissural neurons, and 3 DIV E15 dorsal root ganglion neuron cultures using TRIzol (Invitrogen Life Technologies, Burlington, Ontario, Canada). For amplification of individual sAC exons or Rho-associated, coiled-coil containing protein kinase 1 (ROCKI), genomic DNA was removed from RNA samples with RNase-free DNase I (Illustra RNAspin Mini RNA Isolation Kit; GE Healthcare, Buckinghamshire, UK). RNA samples were then heated to $95^{\circ} \mathrm{C}$ for $2-3$ min to denature the DNase I. Reverse transcriptase (RT)-PCR was performed with $0.5 \mu \mathrm{g}$ of total RNA per reaction using the QIAGEN OneStep RT-PCR Kit (Qiagen, Mississauga, Ontario, Canada). All primers, except for DCC, were annealed at $60^{\circ} \mathrm{C}$. The primer pair for amplification of rat DCC was annealed at $55^{\circ} \mathrm{C}$. The following PCR primers were used: rat $\mathrm{N}$ terminal (N-term), CGAGCAGCTGGTGGAGATCC and GCGTGAGTGATCTCGTCAGGGGC; rat C terminal (Cterm), CCTGCTTCTCCCTGCTGTG and GCAGGAGTAAAGTCCCAGG; rat C1, AGCAGCTGGTGGAGATCCT and TTCAATCATGCTCCGATCAC; rat C2, TCATAGGATCAGCCATCCAAG and AAAAGTAGGCTGGCAGGTTG; mouse C1, AACAGCTCGTGGAGATCCT and TTCAATCATGCTCCGATCAC; mouse C2, TCATAGGCTCAGCCATCCAAG and AAAAGTAGGCTGGTAGG; rat exon 4, AGAAGTTCAGCACAGCCATGT and TCGCACTTATGTAGTAGTTGAGGA; rat exon 6, GTGGAAAGTGGAACGAAAGC and CTCCTTGGCTTCAAACAAGC; rat exon 7, CTTGCTCAGAACATGGCTCA and ATCCGGAATCCTCTCGATTT; rat exon 10, TGTGACGATCGTGTTT-
GTGA and TCAAGACGGAAGTGATGTGC; rat exon 11, CCTCTGTGTCTTCGGTTTCC and GGACCTGAGAGCAGAAGTCG; rat exon 12, GCCAGTGGGATTGTCTTCTG and CACAGTGTGTCCAACGATCC; rat exon 13, CAACCTGCCAGCCTACTTTT and TTTCTCATTGAGGCCCAGAC; rat DCC, CCGGAATTCCCACCTATGAGTGCA and GTCCGCTCGAGCAATGCATGTCAAAAGG; rat ROCKI, GTAATCGGCAGAGGTGCATT and TCCAGACTTATCCAGCAGCA. Equal volumes of RT-PCR products were separated on a 1 or $3 \%$ agarose gel.

cAMP detection. 2 DIV commissural neuron and 3 DIV DRG cultures were stimulated with either $10 \mu \mathrm{M}$ forskolin, $0.1 \mu \mathrm{M}$ PACAP, or various concentrations of netrin-1. Stimulations were done for $5 \mathrm{~min}$ in the absence of IBMX or for $15 \mathrm{~min}$ in the presence of $0.5 \mu \mathrm{M}$ IBMX. cAMP levels were measured using either parameter cAMP ELISA (R\&D Systems, Minneapolis, MN) or cAMP EIA (Assay Design, Ann Arbor, MI) kits. Absorbance in each well was measured on a Model 680 microplate reader (Bio-Rad, Hercules, CA). Concentrations of cAMP were normalized across experiments relative to the average value in culture media alone.

Immunohistochemistry. Embryos were fixed in 4\% paraformaldehyde in PBS overnight, $30 \mu \mathrm{m}$ cryostat sections were cut, and axons were visualized with antibodies against NFM and Alexa 488 secondary antibodies.

\section{Results}

\section{Intact spinal ventral commissure in embryonic sAC}

\section{knock-out mice}

sAC knock-out mice contain an internal ribosome entry site (IRES)-LacZ/neomycin cassette that replaces exons 2-4, deleting sequence encoding a portion of the $\mathrm{C} 1$ domain of sAC (Fig. 1A) (Esposito et al., 2004). The C1 domain combines with C2 to form the cyclase catalytic domain (Fig. 1A) (Kamenetsky et al., 2006). In these mice, RNA transcription proceeds through the inserted IRES-LacZ/neomycin cassette and RNA encoding C2 is produced. Consistent with this, using RT-PCR, we detected mRNA transcripts encoding the $\mathrm{C} 2$, but not the $\mathrm{C} 1$ region in testis of adult sAC-null mice (Fig. $1 B$ ). However, because of a frame shift introduced by the transgene, the $\mathrm{C} 2$ portions of sAC are not translated and neither sAC protein nor its activity are detectable in testis and spermatozoa of knock-out animals (Sinclair et al., 2000; Esposito et al., 2004; Hess et al., 2005).

The absence of netrin-1 or its receptor DCC in mice results in disruption of major axon tracts and early postnatal lethality (Serafini et al., 1996; Fazeli et al., 1997). sAC-null mice do not exhibit any obvious neurological deficits and are viable to adulthood, but they have not, to our knowledge, been closely examined for axonal targeting defects (Esposito et al., 2004). To explore the possibility that subtle netrin-dependent axon defects might be present, we examined the spinal ventral commissure in sAC-null mice. Figure $1 C-F$ shows the spinal ventral commissure in sACnull mice is normal and appears indistinguishable from wild type mice. We conclude that SAC is not required for netrin-1mediated guidance of spinal commissural axons.

\section{Minimal expression of soluble adenylate cyclase in netrin-1 responsive neurons}

The expression of sAC in the nervous system during development is controversial. Wu et al. (2006) reported sAC immunofluorescence in embryonic DRG and spinal commissural neurons using antibodies raised against the $50 \mathrm{kDa}$ splice variant of human sAC (Zippin et al., 2003; Wu et al., 2006); however, the immunoreactive species detected by this antibody in these neurons has not been positively identified. Examination of the NCBI Unigene expressed sequence tag (EST) database for transcriptionally active genes indicates that netrin-1, its receptor DCC and six transmembrane adenylyl cyclases are expressed in the embryos of 


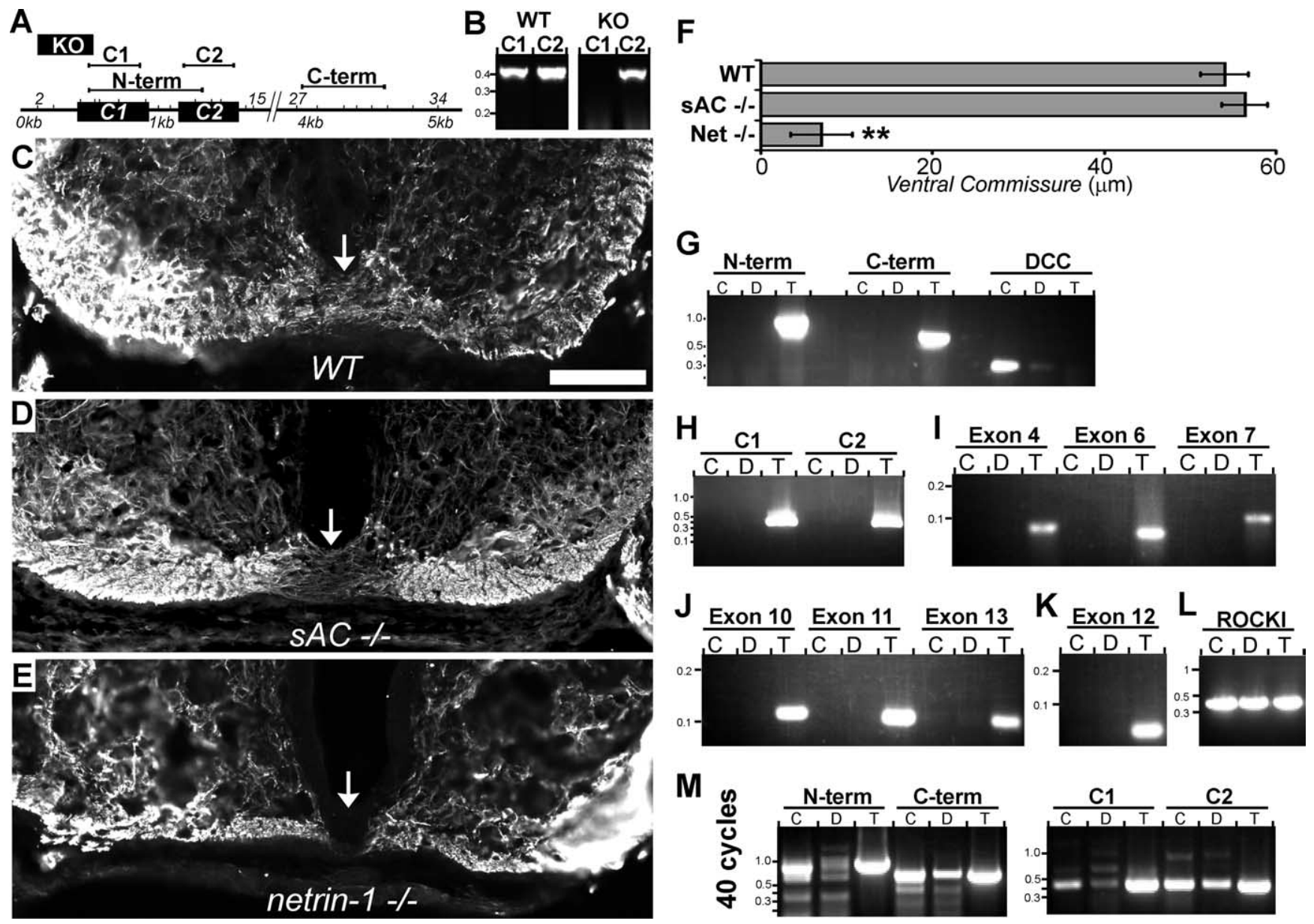

Figure 1. Normal spinal ventral commissure in SAC-deficient mice and weak sAC expression in embryonic DRG or spinal commissural neurons. $A$, Schematic of rat sAC mRNA indicating exon boundaries, the location of the SAC knock-out (KO) mouse insertion, as well as the N-term, C-term, C1, and C2 primers. B, RT-PCR analysis of adult testis in wild-type (WT) and sAC knock-out mice using primer sets $\mathrm{C} 1$ and $\mathrm{C}$. C $C$, Ventral spinal cords of WT, SAC KO, and netrin- 1 KO immunolabeled for NFM; arrows indicate ventral commissure. Scale bar, $100 \mu \mathrm{m}$. $F$, Quantification of the height of the ventral commissures of wild-type and knock-out mice $\left({ }^{* *} p<0.01\right)$. Error bars indicate SEM. G, $\boldsymbol{H}, \mathrm{RT}-\mathrm{PCR}$ analysis of rat testis (T), as well as embryonic spinal commissural (C) and DRG (D) neurons using the N-term, C-term, $C 1$, and $C 2$ primer sets $(\boldsymbol{A})$. I- $\boldsymbol{K}, \mathrm{RT}$-PCR analysis of individual exons longer than 40 base pairs within the $\mathrm{C}$ and $\mathrm{C}$ domains of sAC. $\boldsymbol{L}$, The integrity of these DNase-treated RNA preparations in $\boldsymbol{I}-\boldsymbol{K}$ was confirmed by the amplification of the ROCKI kinase. $\boldsymbol{M}$, After increasing the number of cycles from 30 to 40 , amplification products of the appropriate MW became visible in embryonic DRG and spinal commissural neurons using the $\mathrm{N}$-term, C-term, C1, and C2 primers.

mice, rats, and humans during the period when axons are extending in response to netrin-1. In contrast, ESTs encoding sAC are not detected in embryos of these species during this period.

To directly examine sAC expression in neurons during neural development, RT-PCR analysis with 30 cycles of amplification was carried on isolated DRG and spinal commissural neurons at ages when netrin-1 is required as an axon guidance cue. Using RT-PCR and primer sequences identical to those previously applied to document low levels of sAC expression in total adult brain mRNA (primer sets N-term and C-term) (Sinclair et al., 2000), we readily detected sAC transcripts in testis, but not in embryonic DRG or spinal commissural neurons (Fig. 1G). To address the possibility that an alternatively spliced sAC may be present in these neurons, we amplified the sequences encoding the $\mathrm{C} 1$ and $\mathrm{C} 2$ domains of sAC, but again, sAC expression was not detected in DRG or spinal commissural neurons (Fig. $1 \mathrm{H}$ ). We then amplified mRNA sequence from each exon $>40 \mathrm{bp}$ in length within the $\mathrm{C} 1$ (exons 4, 6, and 7) and $\mathrm{C} 2$ (exons 10-13) regions. mRNA encoding these exon sequences were readily amplified from testis, but were not detected in embryonic DRG or spinal commissural neurons (Fig. 1 I-L). As a final test, we increased the number of amplification cycles from 30 to 40 to enhance the possibility of detecting extremely rare mRNA transcripts. Using this elevated number of cycles, several amplification products were detected with each of the $\mathrm{N}$-term, $\mathrm{C}$-term, $\mathrm{C} 1$, and $\mathrm{C} 2$ primers (Fig. $1 M$ ). In each case, a band of the expected size was detected, indicating very low levels of sAC expression in embryonic DRG and spinal commissural neurons.

Netrin-1 does not elevate cAMP levels in embryonic DRG neurons

To determine whether these very low levels of sAC might contribute functionally to netrin-1-mediated axon guidance, we examined whether netrin-1 stimulation lead to cAMP production. $\mathrm{Wu}$ et al. (2006) report that $300 \mathrm{ng} / \mathrm{ml}$ netrin-1 applied for $15 \mathrm{~min}$ induces a $40 \%( \pm 50 \%, n=3)$ increase in cAMP production in embryonic DRGs that had been cultured in $100 \mathrm{ng} / \mathrm{ml} \mathrm{NGF}$ for $3 \mathrm{~d}$. However, axon outgrowth from DRGs is maximal at NGF concentrations of $\sim 2.5-5.0 \mathrm{ng} / \mathrm{ml}$ and is sharply reduced at NGF concentrations of $50-100 \mathrm{ng} / \mathrm{ml}$ (Fig. 2A).

We assessed netrin-induced cAMP production in neurons maintained in low, moderate or high concentrations of NGF $(0.8$, 2.5, and $100 \mathrm{ng} / \mathrm{ml}$, respectively). As a positive control, DRG neurons were exposed to PACAP, which induces activity of trans- 


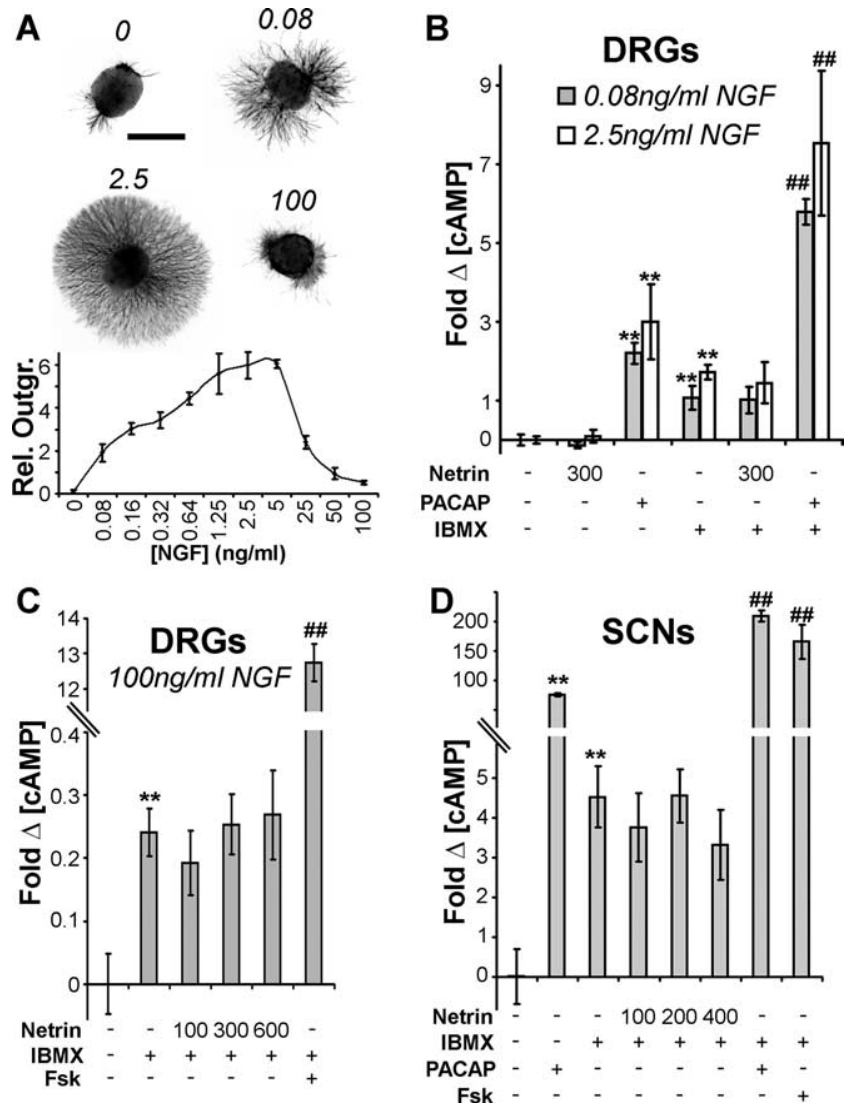

Figure 2. Netrin-1 does not induce CAMP production in DRG neurons or spinal commissural neurons. $A$, NGF-induced outgrowth from E15 DRG explants peaks between 1.25 and $5 \mathrm{ng} / \mathrm{ml}$. Rel. outgr., Relative outgrowth. $B$, CAMP ELISAs on E15 DRG neurons cultured for 3 DIV in 0.08 or $2.5 \mathrm{ng} / \mathrm{mINGF}$. C, CAMP ELISAs on E15 DRG neurons cultured for 3 DIV in $100 \mathrm{ng} / \mathrm{mI} \mathrm{NGF.} \mathrm{D,} \mathrm{CAMP}$ ELISAs on 2 DIV E14 spinal commissural neurons (SCNs). Netrin- 1 concentrations are in ng/ml. Fsk, Forskolin. The axis in $\boldsymbol{C}$ and $\boldsymbol{D}$ are discontinuous. Scale bar, $0.5 \mathrm{~mm} .{ }^{* *} p<0.01$ relative to media alone; ${ }^{\# \#} p<0.01$ relative media with only IBMX. Error bars indicate SEM.

membrane adenylyl cyclase through a G-protein coupled receptor-dependent pathway (Hashimoto et al., 2006). In neurons maintained at 0.08 or $2.5 \mathrm{ng} / \mathrm{ml} \mathrm{NGF,} \mathrm{PACAP} \mathrm{exposure}$ induced a robust increase in cellular cAMP levels in both the presence and absence of the phosphodiesterase inhibitor IBMX, which inhibits the breakdown of cAMP (Fig. $2 B)(>200 \%, n=3$, $p<0.01)$. Netrin-1 did not change the cAMP concentration at any of the concentrations of NGF tested, regardless of the presence of IBMX (Fig. 2B, C). We conclude that netrin-1 does not evoke cAMP production in embryonic DRG neurons.

\section{Netrin-1 does not induce cAMP production in embryonic spinal commissural neurons}

$\mathrm{Wu}$ et al. (2006) suggest that netrin-1 evokes an attractive response in DRG neurons based on growth cone expansion and an increased rate of axon extension; however, in vivo and in vitro evidence argue that netrin-1 repels these axons (Watanabe et al., 2006). In contrast, it is certain that netrin- 1 is a chemoattractant for embryonic spinal commissural axons (Kennedy et al., 1994; Serafini et al., 1996). Using cAMP immunocytochemistry, phospho-CREB immunoblotting, and ELISA techniques, we have previously provided evidence that netrin-1 does not elevate cAMP in spinal commissural neurons (Bouchard et al., 2004; Moore and Kennedy, 2006). These studies, however, did not apply the phosphodiesterase inhibitor, IBMX, which should en- hance the detection of small cAMP transients. Here, using a stimulation strategy identical to that applied by Wu et al. (2006) to DRG neurons (pretreat for 5 min with $0.5 \mathrm{~mm}$ IBMX, stimulate for 15 min with netrin-1), we report that netrin-1 did not alter the concentration of CAMP across a broad range of netrin-1 concentrations (Fig. $2 \mathrm{D}$ ). In contrast, application of PACAP as a positive control induced robust cAMP production in spinal commissural neurons (Fig. 2D) $(762 \pm 29 \%, n=6$, increase applied on its own; $2100 \pm 92 \%, n=6$, increase in the presence of IBMX).

\section{Discussion}

In vertebrates, sAC is expressed at a high level in testis and is essential for normal sperm motility (Sinclair et al., 2000; Esposito et al., 2004). Outside of this role, sAC may function as a bicarbonate sensor in tissues that respond to or regulate bicarbonate levels, such as kidney, choroid plexus, small intestine, lungs, and leukocytes (Chen et al., 2000; Geng et al., 2005; Han et al., 2005; Wang et al., 2005; Schmid et al., 2007). This expression, however, appears to mediate nonessential functions as sAC-null female mice are viable, fertile, and exhibit no obvious abnormal phenotype (Esposito et al., 2004).

Notably, Western blot (Chen et al., 2000) and in situ hybridization (supplemental Fig. 1, available at www.jneurosci.org as supplemental material) (Lein et al., 2007) analyses detected sAC expression in adult rat and mouse brain choroid plexus, but not in neurons. This is consistent with a study that detected sAC transcripts in adult rat brain mRNA using RT-PCR but not by northern blot analysis (Sinclair et al., 2000), likely because of the greater sensitivity of RT-PCR. We conclude that expression by bicarbonate sensitive cells in choroid plexus, and perhaps also in blood, underlies the relatively low level of sAC expression reported in the adult mammalian CNS by RT-PCR and analyses of EST databases (Sinclair et al., 2000; Geng et al., 2005; Han et al., 2005).

Critical to the issue of whether sAC contributes to axon guidance, sAC mRNA transcripts are not reported in the NCBI Unigene database for human, mouse, or rat embryos as axons are extending to their targets (see Unigene clusters Hs.320892; Mm.66952; Rn.42892). Furthermore, although the axon guidance function of netrin-1 is conserved in Drosophila melanogaster and Caenorhabditis elegans, no ortholog of sAC is present in the genomes of these species (Roelofs and Van Haastert, 2002). These findings support the conclusion that $\mathrm{sAC}$ is not required for axon chemoattraction to netrin-1.

Axons will turn toward a source of a membrane permeable cAMP analog (Gundersen and Barrett, 1980; Lohof et al., 1992). Although this demonstration suggested that axon guidance cues might evoke a chemoattractant response by triggering cAMP production, this mechanism does not underlie responses made to all chemoattractants. If cAMP production is a required component of the signal transduction cascade activated by a guidance cue, two criteria must be met: (1) the guidance cue must be capable of inducing cAMP production and (2) global elevation of cAMP must disrupt turning. Consistent with this, a gradient of $\mathrm{PACAP}$ rapidly induces robust CAMP production in a receptive axonal growth cone and this evokes chemoattraction (Fig. $2 B, D$ ) (Hashimoto et al., 2006). Additionally, axonal attraction to an extracellular gradient of PACAP is disrupted when cAMP is elevated globally (Guirland et al., 2003). Netrin-1 meets neither criterion. We have demonstrated that netrin-1 does not elevate cAMP levels in cells that respond to netrin-1 as a chemoattractant (Fig. 2D) (Bouchard et al., 2004; Moore and Kennedy, 2006). Moreover, axon turning to netrin-1 is not disrupted by global 
elevation of cAMP (Ming et al., 1997; Moore and Kennedy, 2006). Rather, elevating cAMP concentration in an axon enhances chemoattraction to netrin-1 (Moore and Kennedy, 2006).

In summary, based on the absence of axon guidance defects in sAC-null mice, the limited expression of sAC within DRG neurons and spinal commissural neurons, and the absence of sAC homologues in D. melanogaster and C. elegans we conclude that sAC is not required for netrin-1-mediated axon guidance. Although cAMP production is a downstream component of the chemoattractant response to some guidance cues, including PACAP, current evidence indicates a fundamentally different role for cAMP in axonal responses to netrin-1. Specifically, cAMP acts as a modulator of netrin-1-mediated axonal chemoattraction that regulates the recruitment of DCC to the growth cone plasma membrane (Ming et al., 1997; Bouchard et al., 2004; Moore and Kennedy, 2006).

\section{References}

Barallobre MJ, Pascual M, Del Rio JA, Soriano E (2005) The Netrin family of guidance factors: emphasis on Netrin-1 signalling. Brain Res Brain Res Rev 49:22-47.

Bouchard JF, Moore SW, Tritsch NX, Roux PP, Shekarabi M, Barker PA, Kennedy TE (2004) Protein kinase A activation promotes plasma membrane insertion of DCC from an intracellular pool: A novel mechanism regulating commissural axon extension. J Neurosci 24:3040-3050.

Chen Y, Cann MJ, Litvin TN, Iourgenko V, Sinclair ML, Levin LR, Buck J (2000) Soluble adenylyl cyclase as an evolutionarily conserved bicarbonate sensor. Science 289:625-628.

Cooper DM (2003) Regulation and organization of adenylyl cyclases and cAMP. Biochem J 375:517-529.

Esposito G, Jaiswal BS, Xie F, Krajnc-Franken MA, Robben TJ, Strik AM, Kuil C, Philipsen RL, van DM, Conti M, Gossen JA (2004) Mice deficient for soluble adenylyl cyclase are infertile because of a severe sperm-motility defect. Proc Natl Acad Sci USA 101:2993-2998.

Fazeli A, Dickinson SL, Hermiston ML, Tighe RV, Steen RG, Small CG, Stoeckli ET, Keino-Masu K, Masu M, Rayburn H, Simons J, Bronson RT, Gordon JI, Tessier-Lavigne M, Weinberg RA (1997) Phenotype of mice lacking functional Deleted in colorectal cancer (Dcc) gene. Nature 386:796-804

Geng W, Wang Z, Zhang J, Reed BY, Pak CY, Moe OW (2005) Cloning and characterization of the human soluble adenylyl cyclase. Am J Physiol Cell Physiol 288:C1305-C1316.

Guirland C, Buck KB, Gibney JA, DiCicco-Bloom E, Zheng JQ (2003) Direct cAMP signaling through G-protein-coupled receptors mediates growth cone attraction induced by pituitary adenylate cyclase-activating polypeptide. J Neurosci 23:2274-2283.

Gundersen RW, Barrett JN (1980) Characterization of the turning response of dorsal root neurites toward nerve growth factor. J Cell Biol 87:546-554.

Hall AK (2006) Rodent sensory neuron culture and analysis. In: Current protocols in neuroscience (Taylor G, ed), pp 3.19.1-3.19.13. Hoboken, NJ: Wiley.

Han H, Stessin A, Roberts J, Hess K, Gautam N, Kamenetsky M, Lou O, Hyde E, Nathan N, Muller WA, Buck J, Levin LR, Nathan C (2005) Calciumsensing soluble adenylyl cyclase mediates TNF signal transduction in human neutrophils. J Exp Med 202:353-361.

Hashimoto H, Shintani N, Baba A (2006) New Insights into the Central PACAPergic System from the Phenotypes in PACAP- and PACAP Receptor-Knockout Mice. Ann N Y Acad Sci 1070:75-89.

Hess KC, Jones BH, Marquez B, Chen Y, Ord TS, Kamenetsky M, Miyamoto C, Zippin JH, Kopf GS, Suarez SS, Levin LR, Williams CJ, Buck J, Moss SB
(2005) The "soluble" adenylyl cyclase in sperm mediates multiple signaling events required for fertilization. Dev Cell 9:249-259.

Hopker VH, Shewan D, Tessier-Lavigne M, Poo M, Holt C (1999) Growthcone attraction to netrin-1 is converted to repulsion by laminin-1. Nature 401:69-73.

Huber AB, Kolodkin AL, Ginty DD, Cloutier JF (2003) Signaling at the growth cone: ligand-receptor complexes and the control of axon growth and guidance. Annu Rev Neurosci 26:509-563.

Kamenetsky M, Middelhaufe S, Bank EM, Levin LR, Buck J, Steegborn C (2006) Molecular details of cAMP generation in mammalian cells: a tale of two systems. J Mol Biol 362:623-639.

Kennedy TE, Serafini T, de la Torre JR, Tessier-Lavigne M (1994) Netrins are diffusible chemotropic factors for commissural axons in the embryonic spinal cord. Cell 78:425-435.

Lein ES, et al (2007) Genome-wide atlas of gene expression in the adult mouse brain. Nature 445:168-176.

Lohof AM, Quillan M, Dan Y, Poo MM (1992) Asymmetric modulation of cytosolic cAMP activity induces growth cone turning. J Neurosci 12:1253-1261.

Ming GL, Song HJ, Berninger B, Holt CE, Tessier-Lavigne M, Poo MM (1997) cAMP-dependent growth cone guidance by netrin-1. Neuron 19:1225-1235.

Moore SW, Kennedy TE (2006) Protein kinase A regulates the sensitivity of spinal commissural axon turning to netrin-1 but does not switch between chemoattraction and chemorepulsion. J Neurosci 26:2419-2423.

Roelofs J, Van Haastert PJ (2002) Deducing the origin of soluble adenylyl cyclase, a gene lost in multiple lineages. Mol Biol Evol 19:2239-2246.

Schmid A, Sutto Z, Nlend MC, Horvath G, Schmid N, Buck J, Levin LR, Conner GE, Fregien N, Salathe M (2007) Soluble adenylyl cyclase is localized to cilia and contributes to ciliary beat frequency regulation via production of cAMP. J Gen Physiol 130:99-109.

Serafini T, Kennedy TE, Galko MJ, Mirzayan C, Jessell TM, Tessier-Lavigne M (1994) The netrins define a family of axon outgrowth-promoting proteins homologous to C. elegans UNC-6. Cell 78:409-424.

Serafini T, Colamarino SA, Leonardo ED, Wang H, Beddington R, Skarnes WC, Tessier-Lavigne M (1996) Netrin-1 is required for commissural axon guidance in the developing vertebrate nervous system. Cell 87:1001-1014.

Shirasaki R, Mirzayan C, Tessier-Lavigne M, Murakami F (1996) Guidance of circumferentially growing axons by netrin-dependent and -independent floor plate chemotropism in the vertebrate brain. Neuron 17:1079-1088.

Sinclair ML, Wang XY, Mattia M, Conti M, Buck J, Wolgemuth DJ, Levin LR (2000) Specific expression of soluble adenylyl cyclase in male germ cells. Mol Reprod Dev 56:6-11.

Tasken K, Aandahl EM (2004) Localized effects of cAMP mediated by distinct routes of protein kinase A. Physiol Rev 84:137-167.

Wang Y, Lam CS, Wu F, Wang W, Duan Y, Huang P (2005) Regulation of CFTR channels by $\mathrm{HCO}(3)$-sensitive soluble adenylyl cyclase in human airway epithelial cells. Am J Physiol Cell Physiol 289:C1145-C1151.

Watanabe K, Tamamaki N, Furuta T, Ackerman SL, Ikenaka K, Ono K (2006) Dorsally derived netrin 1 provides an inhibitory cue and elaborates the 'waiting period' for primary sensory axons in the developing spinal cord. Development 133:1379-1387.

Wu KY, Zippin JH, Huron DR, Kamenetsky M, Hengst U, Buck J, Levin LR, Jaffrey SR (2006) Soluble adenylyl cyclase is required for netrin-1 signaling in nerve growth cones. Nat Neurosci 9:1257-1264.

Zippin JH, Chen Y, Nahirney P, Kamenetsky M, Wuttke MS, Fischman DA, Levin LR, Buck J (2003) Compartmentalization of bicarbonatesensitive adenylyl cyclase in distinct signaling microdomains. FASEB J $17: 82-84$ 